\title{
Black soldier fly and yellow mealworm live larvae for broiler chickens: Effects on bird performance and health status
}

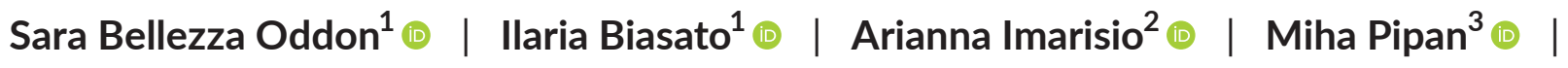 \\ Dominik Dekleva $^{3} \odot$ | Elena Colombino ${ }^{2} \odot$ | Maria Teresa Capucchio ${ }^{2} \odot$ |

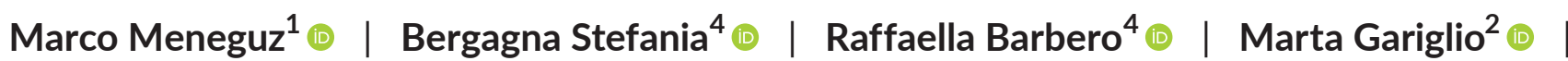 \\ Sihem Dabbou ${ }^{5,6}$ ( | Edoardo Fiorilla ${ }^{2} \odot$ | Laura Gasco ${ }^{1} \odot$ | Achille Schiavone $^{2} \odot$
}

${ }^{1}$ Department of Agricultural, Forest and Food Sciences, University of Turin, Grugliasco, Italy

${ }^{2}$ Department of Veterinary Sciences, University of Turin, Grugliasco, Italy

${ }^{3}$ Entomics Biosystems, Cambridge, UK

${ }^{4}$ Veterinary Medical Research Institute for Piemonte, Liguria and Valle d'Aosta,

Turin, Italy

${ }^{5}$ Center Agriculture Food Environment, University of Trento, Trento, Italy

${ }^{6}$ Research and Innovation Centre, Fondazione Edmund Mach, San Michele all'Adige, Italy

\section{Correspondence}

Ilaria Biasato, Department of Agricultural, Forest and Food Sciences, University of Turin, Grugliasco, Italy.

Email: ilaria.biasato@unito.it

Funding information

The research was supported by the European Knowledge and Innovation Community (KIC), within the EIT Food program 'FROM WASTE TO FARM: insect larvae as tool for welfare improvement in poultry' (Project ID 19122).

\begin{abstract}
The commercial broiler chicken strains are the result of successful selection programmes. Most of the problems related to welfare arise from the high growth rate and body weight. The use of environmental enrichments in intensive farming could have a positive effect on birds by increasing animal welfare. The aim of the study was to evaluate the effects of Hermetia illucens (HI) and Tenebrio molitor (TM) live larvae in the diets of broiler chickens on growth performance, carcass yield and health status. A total of 180 four-day-old male broiler chickens (Ross 308 ) were randomly allotted to 18 pens. Each pen was assigned to one of the three dietary treatments (6 replicates/treatment, 10 birds/replicate) as follows: (i) control diet (C): commercial feed (two feeding phases: starter [4-11 days] and grower [12-38 days]), (ii) $\mathrm{HI}: \mathrm{C}+5 \%$ of the expected daily feed intake (DFI) HI live larvae (calculated on dry matter [DM]) and (iii) TM: C + 5\% of DFI TM live larvae (DM). At 39 days of age, birds were slaughtered. Growth performance parameters were overall not affected by dietary treatments, except for the grower phase feed conversion ratio (FCR) and the overall FCR being better in the TM broilers than the others $(p<0.01)$. No differences were observed for slaughtering performance and haematological and serum parameters, except for the spleen relative weight being higher $(p<0.01)$ in the birds administered with larvae when compared to the $C$ group. Gut morphometric indexes and histopathological alterations were not influenced by insect larvae administration. In conclusion, the administration in limited quantities of $\mathrm{HI}$ and TM live larvae as environmental enrichment has no negative effects on broiler chicken growth performance and health status. A behavioural study could confirm that live insect larvae represent a novel natural environmental enrichment in broiler farming.
\end{abstract}

KEYWORDS

black soldier fly, environmental enrichment, growth performance, gut health, insect larvae, poultry, yellow mealworm 


\section{1 | INTRODUCTION}

In Europe, poultry industry has progressively moved on towards an industrialized and vertically integrated broiler production, with substantial increase in per capita poultry consumption and significant decline of market prices for broilers (Magdelaine et al., 2019). Currently, the commercial broiler chicken strains are the result of successful selection programmes for two important productive characteristics: the rapid growth and the body conformation (Scheuermann et al., 2003). The maximization of the productive efficiency has progressively led to the adoption of intensive indoor systems to carry out the broiler chicken production (Robins \& Phillips, 2011). However, the intensive rearing may frequently cause the parallel degradation of the welfare status of the birds, thus being furtherly exacerbated by barren environment (Riber et al., 2018). Therefore, environmental enrichments have recently been proposed as effective tools to create a more diverse rearing habitat for the animals. The environmental enrichment is generally defined as an improvement in the biological functioning of captive animals resulting from modification of their environment (Newberry, 1995). Since in nature birds eat insects in larval, pupal and adult forms, they can be used as environmental and nutritional enrichments in broiler chicken farming (Zuidhof et al., 2003). The recovery of a natural behaviour could therefore have positive effects on the animal welfare and, consequently, on the breeding and final product images that the consumer creates. Consumers are increasingly interested in the issue of animal welfare, as they seem to prefer food products which are perceived to be more 'animal friendly' (Harper \& Makatouni, 2002).

The introduction of a natural element, such as the live insect larvae, into a fully artificial breeding could expand the range of behavioural expression and increase the motility of the animals. For this reason, the use of live larvae can be considered a novel, promising environmental enrichment. Indeed, the addition of variable food items (such as the insects) may be attractive for birds and could potentially increase the amount of time spent for the foraging behaviour and, consequently, make animals more active (Koene, 1999; Bizeray et al., 2002).

Currently, the use of insects in animal feed is a topic of growing interest (Gasco et al., 2019). So far, many researchers have focused their attention on the introduction of insect meal in poultry diets. In particular, the available studies investigated the effects of Tenebrio molitor (TM) and Hermetia illucens (HI) larva meal on broiler chicken growth performance and animal health (Bovera et al., 2016; Biasato et al., 2017; Dabbou et al., 2018; Biasato et al., 2019). In the recent years, the interest has also been directed to the use of live insect larvae as feed ingredients or enrichments in poultry nutrition. For this reason, there are few scientific papers on this issue; trials have been carried out on turkeys (Veldkamp \& van Niekerk, 2019) and laying hens (Star et al., 2020) fed HI live larvae, with improved growth performance (in terms of better feed efficiency) having overall been observed. In broiler chickens, on the other hand, the effects of $\mathrm{HI}$ live larvae on animal activity and leg health were recently evaluated (Ipema et al., 2020). The authors observed that the activity was numerically higher and lasted for a longer time in broiler chickens fed $10 \%$ of larvae and 4 times per day when compared to the control birds (Ipema et al., 2020). According to EU legislation, in particular the Commission Regulation No. 999/2001, the use of live insects in poultry feeding is allowed as the feed ban regarding the use of insect-derived proteins does not apply to live insects (IPIFF, 2020).

Nowadays, the standard evaluation of the bird performance has progressively been accompanied by the concomitant assessment of the gut health dynamics, as a healthy, well-functioning intestine is considered a synonymous of animal health and it represents the main determinant of the animal growth (Kogut \& Arsenault, 2016). In particular, the morphometric evaluation of selected gut segments and/or mucosal elements (such as the crypts and the villi)-together with the blood profile and organ histopathological analyses-has previously been resulted to be an effective, easy-to-use approach to simultaneously characterize the gut health and overall health status of broilers (Biasato et al., 2018). However, such analyses have not been performed yet on birds administered with live insect larvae as environmental enrichments.

Based on the above-mentioned background, the goal of this study is to evaluate the effects of the administration of TM and $\mathrm{HI}$ live larvae on performance, blood profile, gut morphology and organ histopathology in broiler chickens.

\section{2 | MATERIALS AND METHODS}

\section{1 | Birds and husbandry}

The present trial was performed in the poultry facility of the University of Turin (Italy). The experimental protocol (ID: 814715) was approved by the Bioethical Committee of the University of Turin (Italy). A total of 180 four-day-old male broiler chickens (Ross 308; average initial live weight: $88.6 \pm 9.8 \mathrm{~g}$ ) were randomly allotted to 18 pens. Each pen was $1.20 \mathrm{~m}$ wide $\times 2.20 \mathrm{~m}$ long and was covered with rice hulls as litter. The poultry house was equipped with a waterproof floor and walls, completely covered by tiles and provided with an automatic ventilation system. The lighting schedule was 16-h light:8-h darkness for the whole trial. Environmental conditions in the house, temperature and relative humidity, were set according to the Ross guidelines (Aviagen, 2019). The animals and the environmental parameters were daily checked during the whole experimental period.

\section{2 | Diets}

According to birds' requirements (Aviagen 2019), the basal diet was a commercial feed having two feeding phases: starter (1-11 days; metabolizable energy [ME]: $12.5 \mathrm{MJ} / \mathrm{kg}$ and crude protein [CP]: $224 \mathrm{~g} /$ $\mathrm{kg}$ ) and grower (12-38 days; ME: $13.0 \mathrm{MJ} / \mathrm{kg}$ and CP: $220 \mathrm{~g} / \mathrm{kg}$ ) (Fa. ma.ar.co SPA). Each pen was assigned to the dietary treatments (6 replicates/treatment, 10 birds/replicate) as follows: (i) control (C), (ii), $\mathrm{HI}: \mathrm{C}+5 \%$ of the expected daily feed intake [DFI] HI live larvae and 
TABLE 1 Proximate composition of HI and TM larvae

\begin{tabular}{lllll}
$\begin{array}{l}\text { Chemical composition } \\
\text { (as fed basis, \%) }\end{array}$ & $\begin{array}{l}\text { Hl early instar } \\
\text { larvae }\end{array}$ & $\begin{array}{l}\text { HI late instar } \\
\text { larvae }\end{array}$ & $\begin{array}{l}\text { TM early } \\
\text { instar larvae }\end{array}$ & $\begin{array}{l}\text { TM late } \\
\text { instar larvae }\end{array}$ \\
\hline DM & 25.32 & 25.32 & 27.54 & 27.54 \\
\hline CP & 12.01 & 8.07 & 16.78 & 10.82 \\
\hline Ash & 3.05 & 2.00 & 1.69 & 0.90 \\
\hline EE & 0.42 & 1.93 & 0.59 & 5.50 \\
\hline GE (MJ/kg) & 5.03 & 6.76 & 5.90 & 7.65 \\
\hline
\end{tabular}

Abbreviations: $\mathrm{CP}$, crude protein; DM, dry matter; $\mathrm{EE}$, ether extract; GE, gross energy.

${ }^{a}$ Values are reported as mean of duplicate analyses.

(iii) TM: C $+5 \%$ of the expected of DFI TM live larvae. The amount of the live larvae was calculated on the dry matter (DM) of the expected DFI reported in the Ross guidelines (Aviagen, 2019). To prevent the chicks from not being able to feed due to the too large size of the larvae, different larvae dimensions were provided in the two growth periods and precisely: early or late instar (length: $0.80 \mathrm{~cm} \pm 0.05$ and $1.5 \pm 0.05 \mathrm{~cm}$, respectively) for starter and grower period respectively. The commercial diet and the water were distributed ad libitum in all the treatments. For each pen, the daily larvae quantity was placed in two plates and distributed at 11.00 a.m. To avoid the bias, two plates with a known amount of control feed inside were also provided to the $C$ animals to create the same interaction with the operators in all the treatments. When the larvae intake was ended in all the boxes, the leftover $C$ feed was returned in the feeders. Every day, the time spent by birds eating the larvae was recorded in the larvae treatments only by stopwatch, starting from the moment the plates with the larvae were located in the box until the plates were empty. Samples of larvae were periodically collected, killed by freezing $\left(-20^{\circ} \mathrm{C}\right)$ and stored to carry out the chemical analyses.

\section{3 | Larvae preservation}

The quantity of $\mathrm{HI}$ and TM larvae needed to satisfy the $5 \%$ of the DFI was weekly sent by Entomics Biosystems (Cambridge, UK) and by Italian Cricket Farm (Turin, Italy) respectively.

Since the HI larvae underwent one day of transport, they were shipped along with the substrate to secure feed. Upon arrival, the larvae were separated from the substrate. According to Holmes et al. (2016), the $\mathrm{HI}$ larvae were kept in a climatic chamber at $16^{\circ} \mathrm{C}$ to trigger the diapause mechanism. The diapause is a dynamic process consisting of several successive phase, and it is generally defined as an endogenously arrest of the direct development that proceeds with an alternative programme of physiological events (Koštál, 2006). As far as TM larvae are concerned, the study of Qin \& Walker (2005) was taken as reference. In particular, as these authors reported that at $5.5^{\circ} \mathrm{C}$, the activity of thermal hysteresis is still found in the haemolymph of TM, a pre-trial (data not reported) to induce diapause was held placing TM larvae at different refrigeration temperatures $\left(6^{\circ} \mathrm{C}, 8^{\circ} \mathrm{C}\right.$ and $\left.10^{\circ} \mathrm{C}\right)$. Once returned at room temperature in all cases, the diapause ended. For this trial, it was then decided to store larvae in a climatic chamber at $6^{\circ} \mathrm{C}$.
As viable larva was needed for the chickens to be attracted to the environmental enrichment, prior to administration to birds, the larvae underwent a revitalization phase at a temperature of $28^{\circ} \mathrm{C}$ for $10 \mathrm{~min}$. In this period of time, they reactivated their metabolism and, consequently, their motility.

\section{4 | Chemical analysis}

At each arrival, a sample of larvae was stored $\left(-20^{\circ} \mathrm{C}\right)$ for subsequent analytical evaluation. The larvae samples were subsequently freezedried and ground using cutting mill (MLI 204; Bühler AG). Samples were analysed for: DM (method number 943.01), ash (method number 924.05), crude protein (CP, method number 984.13) and ether extract (EE, method number 2003.05) according to International AOAC (DM, ash, CP: AOAC, 2000; EE; AOAC, 2003). The gross energy (GE) content was determined using an adiabatic calorimetric bomb (C7000; IKA). The $\mathrm{HI}$ and TM larvae proximate composition is shown in Table 1.

\subsection{Growth performance}

At the beginning of the experimental trial, birds were individually labelled with a wing mark. The live weight (LW) of the animals was recorded at an individual level (4, 11 and 38 days of age) using electronic scales (KERN PLE-N v. 2.2; KERN \& Sohn GmbH; d: 0.1). The average daily gain (ADG) and the daily feed intake (DFI) were calculated on pen basis at the end of each growth period (4-11 days; 12-38 days), while the feed conversion ratio (FCR) was calculated on pen basis at the end of each growth period and for the overall experimental trial (4-11 days; $12-38$ days; $4-38$ days). The FCR was calculated by including in the formula the amount ( $\mathrm{g}$ ) of larvae (based on DM: $25.3 \%$ for HI larvae and $27.5 \%$ for TM larvae) intake by the birds.

\section{6 | Slaughtering procedure and recording}

At 39 days of age, after $12 \mathrm{~h}$ of feed withdrawal, final LW was recorded. On the basis of the average final LW, 3 birds/pen (18 broilers/diet) were electrically stunned and slaughtered at a commercial 
TABLE 2 Effects of the dietary treatments on the growth performance of the broiler chickens $(n=6)$

\begin{tabular}{|c|c|c|c|c|c|c|}
\hline \multirow[b]{2}{*}{ Items } & \multirow{2}{*}{$\begin{array}{l}\text { Age } \\
\text { (days) }\end{array}$} & \multicolumn{3}{|c|}{ Dietary treatments ${ }^{a}$} & \multirow[b]{2}{*}{ SEM } & \multirow{2}{*}{$\begin{array}{l}p \\
\text { Value }^{\text {b }}\end{array}$} \\
\hline & & C & $\mathrm{HI}$ & TM & & \\
\hline \multirow[t]{3}{*}{ LW, g } & 4 & 87 & 87 & 88 & 0.38 & 0.796 \\
\hline & 11 & 220 & 216 & 225 & 3.60 & 0.603 \\
\hline & 38 & 2488 & 2527 & 2452 & 22.28 & 0.619 \\
\hline \multirow{2}{*}{$\begin{array}{l}\text { ADG, } \\
\qquad \mathrm{g} / \mathrm{d}\end{array}$} & $4-11$ & 19 & 18 & 20 & 0.49 & 0.610 \\
\hline & $12-38$ & 76 & 72 & 80 & 1.98 & 0.348 \\
\hline \multirow[t]{2}{*}{ DFI, g/d } & $4-11$ & 24 & 22 & 22 & 0.67 & 0.679 \\
\hline & $12-38$ & 110 & 108 & 103 & 3.45 & 0.753 \\
\hline \multirow{3}{*}{$\begin{array}{l}\text { FCR, } \\
\qquad / \mathrm{G}\end{array}$} & $4-11$ & 1.25 & 1.23 & 1.16 & 0.02 & 0.223 \\
\hline & $12-38$ & $1.36^{\mathrm{ab}}$ & $1.39^{\mathrm{a}}$ & $1.32^{b}$ & 0.01 & $* *$ \\
\hline & $4-38$ & $1.37^{\mathrm{a}}$ & $1.38^{\mathrm{a}}$ & $1.31^{\mathrm{b}}$ & 0.01 & $* *$ \\
\hline
\end{tabular}

Abbreviations: ADG, average daily gain; DFI, daily feed intake; FCR, feed conversion ratio; LW, live weight; SEM, standard error of the mean. ${ }^{a}$ Three dietary treatments: $\mathrm{C}=$ control; $\mathrm{HI}: \mathrm{C}+5 \%$ of DFI HI larvae; and TM: C $+5 \%$ of DFI TM larvae.

$\mathrm{b}_{* *} p$ value $<0.01$

abattoir. The plucked and eviscerated carcasses were obtained, and the head, neck, feet and abdominal fat were removed to obtain the chilled carcass. Then, the weight of heart, spleen, bursa of Fabricius, liver, gut, gizzard, glandular stomach, visceral fat, thigh and breast were immediately recorded and the data were expressed as percentage of LW. The caeca from the slaughtered animals were also isolated and photographed orthogonally with a metric scale $(\mathrm{mm})$. The images were subsequently analysed with the software Image ${ }^{\circledR}$-Pro Plus software (6.0 version, Media Cybernetics) in order to record the caecal length.

\section{7 | Haematological and serum parameters}

At slaughter, blood samples were collected from the slaughtered birds. A total of $2.5 \mathrm{ml}$ was placed in an EDTA tube and $2.5 \mathrm{ml}$ in a serum-separating tube. From a drop of blood without anticoagulant, a blood smear was prepared and the May-Grünwald and Giemsa were used as stain (Campbell, 1995). The blood samples previously treated with a 1:200 Natt-Herrick solution were employed for the total red and white blood cell counts through an improved Neubauer haemocytometer. On every slide, one hundred leucocytes, including granular (heterophils, eosinophils and basophils) and non-granular (lymphocytes and monocytes) leucocytes, were counted, and the heterophils-to-lymphocytes $(\mathrm{H} / \mathrm{L})$ ratio was calculated (Salamano et al., 2010).

The serum was obtained by keeping the tubes without anticoagulant in a standing position at room temperature for approximately two hours. Later, the serum was separated by centrifugation (700 g for $15 \mathrm{~min}$ ) and frozen at $-80^{\circ} \mathrm{C}$ until analysis. The total proteins were quantified by means of the 'Biuret method' (Bio Group Medical System kit; Bio Group Medical
System), while the electrophoretic pattern of the serum was obtained using a semi-automated agarose gel electrophoresis system (Sebia Hydrasys ${ }^{\circledR}$ ). The albumin, alaninoaminotransferase $(\mathrm{ALT})$, aspartate aminotransferase (AST), triglycerides, cholesterol, uric acid and HDL serum concentrations were measured by means of enzymatic methods in a clinical chemistry analyser (Screen Master Touch, Hospitex diagnostics Srl.), while the LDL serum concentration was calculated according to the Friedewald formula as follows: total cholesterol-HDL-(triglycerides/5) (Friedewald et al., 1972).

\section{8 | Histomorphological investigations}

The slaughtered birds were also submitted to anatomo-pathological investigations. Samples of intestine (duodenum, jejunum and ileum), liver, spleen, thymus and bursa of Fabricius were collected and processed according to Biasato et al. (2017). The processed samples were submitted to morphometric (gut segments) and histopathological (organs) investigations, following the procedures previously described (Biasato et al., 2017). In addition, gut histopathological findings were separately assessed for mucosa (inflammatory infiltrates) and submucosa (inflammatory infiltrates and gut-associated lymphoid tissue [GALT] activation) for each segment. The total score of each gut segment was obtained by adding up the mucosa and submucosa scores, while the total score of each bird was represented by the mean value of the duodenum, jejunum and ileum scores.

\section{9 | Statistical analysis}

The statistical analysis was performed using IBM SPSS Statistics V26.0.0 software (IBM). Each pen was considered as the experimental unit for the growth performance and larvae intake times $(n=6$ per treatment), while the individual bird was used as the experimental unit to analyse the slaughtering performance, the blood parameters, the gut histomorphology and the histopathological features ( $n=18$ per treatment).

Shapiro-Wilk's test established normality or non-normality of distribution. Growth performance and blood parameters were analysed by means of one-way ANOVA (post hoc test: Bonferroni's multiple comparison test). Both the larvae intake times and the gut histomorphological findings were analysed by fitting a general linear mixed model (GLMM). In the first case, the GLMM allowed the larvae intake minutes to depend on three fixed factors (diet, time and the interaction between the diet and the time). The replicate was included as a random effect to account for repeated measurements on the same pen. In the second case, the GLMM allowed the morphometric indices ( $\mathrm{Vh}, \mathrm{Cd}$ and $\mathrm{Vh} / \mathrm{Cd}$, separately) to depend on three fixed factors (diet, intestinal segment and the interaction between the diet and the intestinal segment). Animal was included as a random effect to account for repeated measurements on the same 
bird. The interactions between the levels of the fixed factors were evaluated by means of pairwise comparisons. The histopathological scores were analysed by means of the Kruskal-Wallis test post hoc test: Dunn's multiple comparison test).

The results were expressed as the mean (growth and slaughtering performance, blood parameters and histopathological features) or least square mean (larvae intake times and gut histomorphological findings) and standard error of the mean (SEM). $p$ values $\leq 0.05$ were considered statistically significant.

\section{3 | RESULTS}

\section{1 | Growth performance}

The data relating to the growth performance parameters are shown in Table 2. The final LW (39 days of age), the ADG and the DFI taking into account the larvae intake did not differ among the groups. The FCR in the starter period was also not affected by the dietary treatment. Differently, the grower period FCR significantly differed among the experimental groups, with the TM birds displaying a better feed efficiency than the $\mathrm{HI}(p<0.01)$. Significant differences were also identified in the overall FCR calculation, as the TM broilers showed a better FCR than the other dietary treatments $(p<0.01)$.

\section{2 | Larva ingestion time}

The broilers fed TM larvae showed lower intake times of larvae than the $\mathrm{HI}$ birds ( $p<0.05$; Figure 1), with the fastest larva consumption being also recorded during the second week of the trial for both the groups $(p<0.05)$.
TABLE 3 Effects of the dietary treatments on the slaughtering performance of the broiler chickens $(n=18)$

\begin{tabular}{|c|c|c|c|c|c|}
\hline \multirow[b]{2}{*}{ Items } & \multicolumn{3}{|c|}{ Dietary treatments ${ }^{a}$} & \multirow[b]{2}{*}{ SEM } & \multirow[b]{2}{*}{$p$ Value $^{\mathrm{b}}$} \\
\hline & C & HI & TM & & \\
\hline LW (g) & 2477 & 2517 & 2442 & 20.13 & 0.741 \\
\hline $\begin{array}{l}\text { Hot carcass } \\
\text { yield (\%LW) }\end{array}$ & 76.48 & 76.01 & 76.07 & 0.153 & 0.402 \\
\hline $\mathrm{CCW}(\mathrm{g})$ & 1853 & 1841 & 1879 & 12.15 & 0.429 \\
\hline $\begin{array}{l}\text { Cold carcass } \\
\text { yield (\%LW) }\end{array}$ & 74.42 & 73.94 & 73.99 & 0.159 & 0.402 \\
\hline $\begin{array}{r}\text { Breast yield } \\
(\% \mathrm{CCW})\end{array}$ & 32.42 & 32.08 & 31.83 & 0.227 & 0.574 \\
\hline $\begin{array}{l}\text { Thigh yield } \\
\text { (\%CCW) }\end{array}$ & 29.76 & 29.47 & 29.02 & 0.168 & 0.205 \\
\hline Spleen (\%LW) & $0.78^{a}$ & $0.94^{b}$ & $0.88^{b}$ & 0.00 & $* *$ \\
\hline Liver (\%LW) & 1.61 & 1.68 & 1.67 & 0.03 & 0.602 \\
\hline $\begin{array}{l}\text { Bursa of } \\
\text { Fabricius } \\
\text { (\%LW) }\end{array}$ & 0.18 & 0.20 & 0.19 & 0.01 & 0.562 \\
\hline Heart (\%LW) & 0.42 & 0.45 & 0.45 & 0.01 & 0.078 \\
\hline Intestine (\%LW) & 3.25 & 3.48 & 3.34 & 0.05 & 0.111 \\
\hline $\begin{array}{l}\text { Glandular } \\
\text { stomach } \\
\text { (\%LW) }\end{array}$ & 0.30 & 0.31 & 0.30 & 0.00 & 0.474 \\
\hline Gizzard (\%LW) & 1.19 & 1.23 & 1.28 & 0.08 & 0.894 \\
\hline $\begin{array}{l}\text { Abdominal fat } \\
\qquad \% \text { LW) }\end{array}$ & 1.33 & 1.24 & 1.29 & 0.03 & 0.598 \\
\hline $\begin{array}{l}\text { Caecal length } \\
(\mathrm{cm})\end{array}$ & 16.92 & 17.25 & 17.14 & 0.03 & 0.771 \\
\hline
\end{tabular}

Abbreviations: CCW, cold carcass weight; LW, live weight; SEM, standard error of the mean.

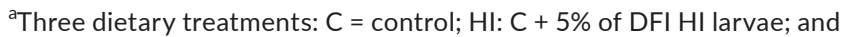
TM: C $+5 \%$ of DFI TM larvae.

$\mathrm{b}^{\mathrm{b} *} p$ value $<0.01$

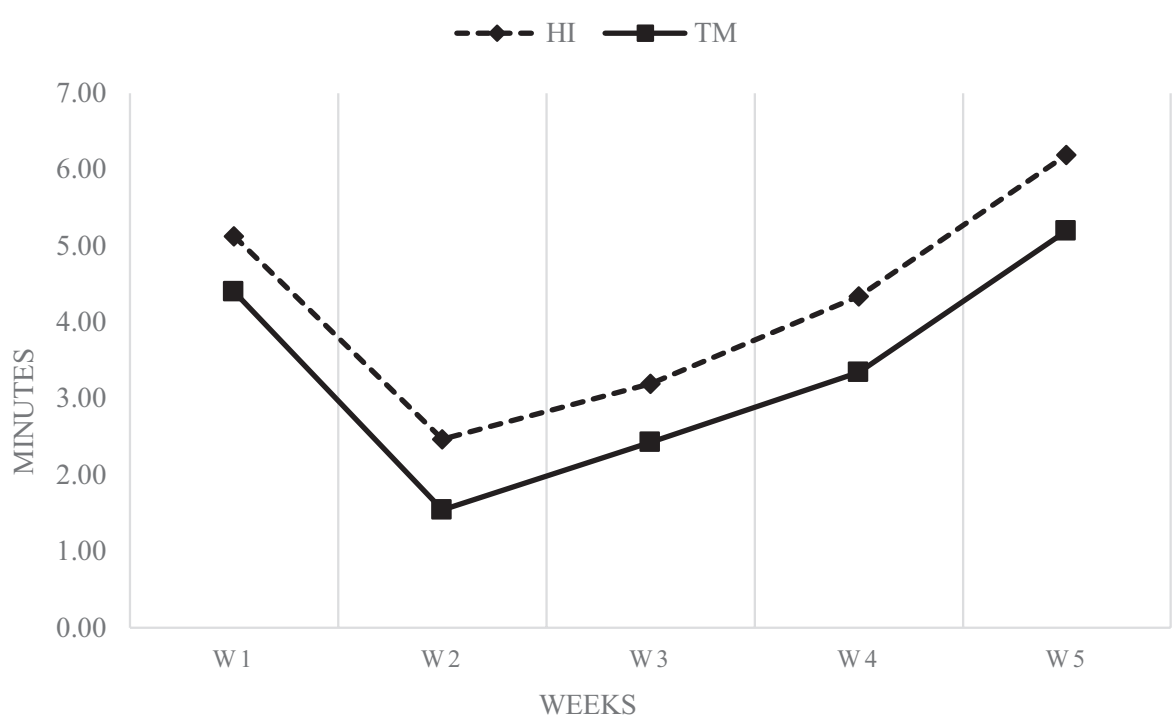

FIGURE 1 Time spent by the broiler chickens on eating the insect larvae 


\begin{tabular}{|c|c|c|c|c|c|}
\hline \multirow[b]{2}{*}{ Items } & \multicolumn{3}{|c|}{ Dietary treatments ${ }^{a}$} & \multirow[b]{2}{*}{ SEM } & \multirow{2}{*}{$\begin{array}{l}p \\
\text { Value }\end{array}$} \\
\hline & C & $\mathrm{HI}$ & TM & & \\
\hline Erythrocytes $\left(10^{6}\right.$ cell $\left./ \mu \mathrm{l}\right)$ & 2.85 & 3.13 & 3.43 & 1.23 & 0.165 \\
\hline Leucocytes $\left(10^{6} \mathrm{cell} / \mu \mathrm{l}\right)$ & 12.49 & 14.15 & 13.13 & 11.26 & 0.836 \\
\hline$H / L$ & 1.09 & 1.13 & 0.91 & 0.07 & 0.361 \\
\hline Albumin (g/dl) & 1.41 & 1.46 & 1.57 & 0.05 & 0.396 \\
\hline $\mathrm{ALT}(\mathrm{U} / \mathrm{L})$ & 3.50 & 2.89 & 6.00 & 0.60 & 0.076 \\
\hline AST (U/L) & 372.67 & 360.33 & 345.06 & 15.70 & 0.779 \\
\hline Cholesterol (mg/dl) & 165.22 & 165.56 & 162.50 & 2.43 & 0.859 \\
\hline Total protein (g/dl) & 8.24 & 8.53 & 9.36 & 0.31 & 0.325 \\
\hline Triglycerides (mg/dl) & 39.94 & 45.61 & 48.44 & 1.75 & 0.131 \\
\hline Uric acid (mg/dl) & 3.86 & 3.47 & 3.13 & 0.24 & 0.468 \\
\hline $\mathrm{HDL}(\mathrm{mg} / \mathrm{dl})$ & 115.50 & 114.67 & 111.67 & 1.45 & 0.534 \\
\hline LDL (mg/dl) & 41.73 & 41.7 & 41.14 & 1.34 & 0.978 \\
\hline
\end{tabular}

TABLE 4 Effects of dietary treatments on the haematochemical parameters of the broiler chickens $(n=18)$

Abbreviations: ALT, alaninoaminotransferase; AST, aspartate aminotransferase; HDL, high-density lipoproteins; H/L, heterophils/lymphocytes; LDL, low-density lipoproteins; SEM, standard error of the mean.

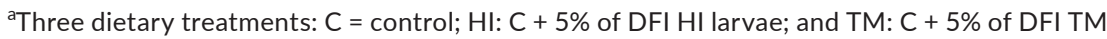
larvae.

TABLE 5 Intestinal morphometric indices in the broiler chickens in relation to diet and intestinal segment $(n=18)$

\begin{tabular}{|c|c|c|c|c|c|c|c|c|c|c|}
\hline Index & \multicolumn{3}{|c|}{ Diet (D) } & \multicolumn{3}{|c|}{ Intestinal segment (IS) } & SEM & \multicolumn{3}{|c|}{$p$ Value $^{\dagger}$} \\
\hline Vh, mm & 1.20 & 1.27 & 1.20 & $1.69^{\mathrm{a}}$ & $1.17^{\mathrm{b}}$ & $0.82^{c}$ & 0.03 & 0.129 & $* * *$ & 0.866 \\
\hline $\mathrm{Cd}, \mathrm{mm}$ & 0.09 & 0.10 & 0.09 & $0.11^{\mathrm{a}}$ & $0.09^{b}$ & $0.08^{c}$ & 0.00 & 0.057 & $* * *$ & 0.576 \\
\hline $\mathrm{Vh} / \mathrm{Cd}$ & 14.01 & 13.55 & 12.80 & $16.61^{\mathrm{a}}$ & $15.21^{\mathrm{a}}$ & $9.46^{\mathrm{c}}$ & 0.47 & 0.159 & $* * *$ & 0.949 \\
\hline
\end{tabular}

Note: The means with different superscript letters (a, b, c) within the same row per fixed effect (i.e. diet, intestinal segment) differ significantly $(p<0.05)$.

Abbreviations: $\mathrm{C}$ control, $\mathrm{HI}$ C $+5 \%$ of DFI HI larvae, TM C $+5 \%$ of DFI TM larvae, SEM standard error of the mean, Vh villus height, Cd crypt depth and $\mathrm{Vh} / \mathrm{Cd}$ villus height-to-crypt depth ratio.

$\dagger^{* * *} p$ value $<0.01$

\section{3 | Slaughtering performance}

No significant differences were overall observed for the slaughtering performance among the experimental treatments, except for the spleen relative weight being higher $(p<0.01)$ in the birds administered with insect larvae when compared to the $C$ group (Table 3 ).

\subsection{Haematological and serum parameters}

As reported in Table 4, the haematological and the serum parameters were not influenced by the dietary treatments.

\section{5 | Histomorphological investigations}

As summarized in Table 5, there was no significant influence of diet and interaction between diet and intestinal segment on the gut morphometric indices. On the contrary, the intestinal segment significantly affected the gut histomorphology $(p<0.001)$. In particular, the duodenum showed greater $\mathrm{Vh}, \mathrm{Cd}$ and $\mathrm{Vh} / \mathrm{Cd}$ than the other gut segments $(p<0.001)$, with morphometric indices being also greater in the jejunum when compared to the ileum $(p<0.001)$.

Absent or mild to moderate histopathological alterations were observed in all the organs from all the experimental treatments, as shown in Table 6. Independently of the insect larvae administration, the spleen showed mild, multifocal white pulp hyperplasia, while mild to moderate, multifocal to diffuse follicular depletion was detected in the bursa of Fabricius. Furthermore, the liver showed mild to moderate, multifocal to diffuse vacuolar degeneration of the hepatocytes, as well as mild to moderate, multifocal lymphoplasmacytic infiltrates, whereas in gut mild to moderate, multifocal to diffuse, mucosal or submucosal lymphoplasmacytic infiltrates with or without GALT activation were observed. No alterations were detected in the thymus. However, the insect larvae administration did not affect the histopathological scores. 
TABLE 6 Histopathological alterations in the broiler chickens $(n=18)$

\begin{tabular}{|c|c|c|c|c|c|}
\hline \multirow[b]{2}{*}{ Items } & \multicolumn{3}{|c|}{ Dietary treatments ${ }^{a}$} & \multirow[b]{2}{*}{ SEM } & \multirow{2}{*}{$\begin{array}{l}p \\
\text { Value }\end{array}$} \\
\hline & C & $\mathrm{HI}$ & TM & & \\
\hline Spleen & 0.05 & 0.32 & 0.38 & 0.06 & 0.062 \\
\hline Thymus & \multicolumn{5}{|c|}{ Absence of alterations } \\
\hline $\begin{array}{l}\text { Bursa of } \\
\text { Fabricius }\end{array}$ & 0.25 & 0.17 & 0.41 & 0.06 & 0.308 \\
\hline Liver & 1.47 & 1.55 & 1.13 & 0.10 & 0.197 \\
\hline Gut & 1.88 & 1.22 & 1.94 & 0.14 & 0.069 \\
\hline
\end{tabular}

Note: The data are expressed as the mean of the scores $(0=$ absence of alterations; 1 = mild alterations; 2 = moderate alterations; 3 = severe alterations). The gut scores resulted from the mean of the three gut segment scores (in turn obtained from the adding of the mucosa and submucosa scores).

Abbreviation: SEM, standard error of the mean.

${ }^{a}$ Three dietary treatments: $\mathrm{C}=$ control; $\mathrm{HI}: \mathrm{C}+5 \%$ of DFI HI larvae; and TM: C $+5 \%$ of DFI TM larvae.

\section{4 | DISCUSSION}

\section{1 | Growth performance}

During the experimental trial, no mortality was recorded. Since in nature birds eat insects, especially in the first weeks of their life (Bruns, 1960), they can be used as environmental and nutritional enrichments in order to improve animal welfare. Chickens that have access to outdoor zone pick up insects at all life stages and eat them on a voluntary basis, thus meaning that they are evolutionarily adapted to insects as a natural part of their diet (Bovera et al., 2016). This is the reason why the birds of the trial were very eager to eat TM and HI larvae. The consumption of the larvae did not affect the final LW, the ADG, the DFI and the starter period FCR. Despite the absence of a statistical significance, in both the feeding phases the DFI displayed by the $C$ birds was found to be numerically greater than that of the larvae-administered group. Therefore, it is conceivable that the nutrient supply derived from dietary insect larvae supplementation may have partially influenced this growth parameter. In the grower phase, the HI birds showed a similar FCR to the $\mathrm{C}$ group, but a worse feed efficiency when compared to the TM broiler chickens. Furthermore, the birds administered with TM larvae showed a better overall FCR when compared to the other groups. The result derived from the comparison of the $C$ group in respect of the $\mathrm{HI}$ animals contrasts with those reported in literature. Indeed, in either the turkey or the laying hens trials, in which the quantity of supplied $\mathrm{HI}$ larvae was equal to $10 \%$ of the DFI, an increase in the feed efficiency was observed (Veldkamp \& van Niekerk, 2019; Star et al., 2020). The turkeys fed HI larvae also showed a higher body weight gain and final body weight than the C treatment (Veldkamp \& van Niekerk, 2019). On the contrary, the productive parameters in the laying hens (laying rate, egg weight, egg mass and mortality rate) were not affected by the larvae administration (Star et al., 2020). Moreover, previous studies have uncovered that the consumption of larvae up to $5 \%$ of the dietary DM has a neutral effect on the growth rate (Ipema et al., 2020). The reduction of FCR in the TM broilers may result from the proximate composition of the larvae. Indeed, in the late instar, the TM larvae of the present study were characterized by a greater quantity of DM, CP and EE than the HI larvae (27.54, 10.82, 5.50; 25.32, 8.07 and 1.93 respectively). Therefore, due to its composition, the TM larvae appear to be more nutritious than the HI larva and its effect appeared in the second period of growth when, proportionally, the quantity of larvae administered became more conspicuous.

\section{2 | Larva ingestion time}

The assessment of the larva ingestion time revealed that broiler chickens were very eager to eat live larvae, especially the TM larvae. The TM broilers showed lower intake times of larvae than the HI birds (3.45 and $4.27 \mathrm{~min}$, respectively), with the fastest larva consumption being also recorded during the second week of the trial for both the groups. Since in the first week the animals needed to adapt to the new feed provided, the larva ingestion time was longer than the second week. In the last three weeks, the intake time slowed down in relation to the increase in body mass of the birds and, consequently, the increased difficulty of movement. The daily assessment of the larvae intake times represents an innovative parameter. In the study conducted with turkeys, in which $\mathrm{HI}$ larvae were provided as $10 \%$ of the DFI, the authors observed that the larvae were consumed within two minutes after provision (Veldkamp \& van Niekerk, 2019). This result is in contrast to the broilers' intake times of the first, third and fourth week, but is similar to the second week (2.17 min). Apart from the different bird species, the discrepancies between the results may be due to dissimilar methods of measuring the intake time-as Veldkamp \& van Niekerk (2019) did not indicate the exact registration start moment-and the type of larvae administration.

\section{3 | Slaughtering performance}

The slaughtering performance of the broiler chickens was overall not influenced by the dietary treatments. On the contrary, the spleen weight was found to be significantly higher in the larvae-fed animals than in the $C$ group. Indeed, the study showed a reactivity of the spleen white pulp in all the groups, with numerically heavier spleen being identified in the treated animals in comparison with the control birds. This outcome can be related to the chitin, a polysaccharide existing in insect that exerts an immunostimulant effect (Gasco et al., 2018). Bovera et al. (2016) have reached the same conclusion, since the authors observed spleen weight gain in animals fed TM meal and associated the results with the antimicrobial and antifungal chitin properties. Furthermore, more stressed animals have a lower spleen weight due to the corticosterone effect, which depresses lymphoid organs growth (Bovera et al., 2016). Consequently, the birds fed insect larvae could be in a situation of greater welfare than the $C$ group. 


\subsection{Haematological and serum parameters}

Prior to this study, no research has focused its attention on evaluating the effects of live larvae on broilers' blood parameters. From a general point of view, blood tests represent useful indicators of the health and metabolic status of the birds. In particular, the assessment of blood biochemical parameters, such as total protein, albumin, AST, ALT, cholesterol, triglycerides, uric acid and others, can serve as diagnostic tool for identifying specific metabolic disturbances occurring in the main organs (Nunes et al., 2018). Considering that the haematological and serological analyses led to similar results among the experimental treatments, it is reasonable to hypothesize that the insect larvae administration has no negative effects on bird metabolic status. Furthermore, the blood values that have been taken into consideration in the present study are within the broiler chickens physiological ranges (Lumej, 2008). The results obtained are also in agreement with those of Biasato et al. (2018) and Dabbou et al. (2018), in which no effect on blood traits was observed in broiler chickens fed with increasing level of insect (HI or TM) meal inclusion (inclusion range 5\%-15\%).

\section{5 | Histomorphological investigations}

So far, no histomorphological investigations have been performed in poultry reared with live insect larvae as environmental enrichments. The broiler chickens administered with insects of the present study showed similar gut morphology when compared to the $\mathrm{C}$ birds, thus probably revealing no significant effects of the live larvae on the intestinal digestion and absorption properties. Differently, increasing inclusion levels of TM (Biasato et al., 2018) and HI (Dabbou et al., 2018) meals in diets for broiler chickens have previously been reported to deeply worsen the gut morphology of the birds (in terms of shorter villi, deeper crypts and reduced $\mathrm{Vh} / \mathrm{Cd}$ ), also determining a significant impairment in their growth performance (in terms of increased FCR). Since the intestinal morphometric indices resulted herein unaffected, the improvement in the feed efficiency observed in the TM broilers was probably related to the better nutritional profile of the TM larvae in comparison with the HI species.

The insect larvae administration in the broiler chickens of the current trial did not lead to the development of significant histopathological alterations, thus confirming the safety of including insects and insect-based products in poultry nutrition. Indeed, dietary insect meal inclusion has already been reported to not exert a negative in fluence on the histological traits of the birds (Biasato et al., 2018; Dabbou et al., 2018).

\section{5 | CONCLUSION}

In conclusion, based on the results obtained in the present study, the $5 \%$ of the expected DFI administration of $\mathrm{HI}$ and TM live larvae has no negative effects on broiler chicken growth performance, with a positive impact on feed efficiency of TM-fed broilers being even observed. Moreover, it has been shown that different insect species in larval stage can differently affect the production parameters of the birds. The live larvae, thanks to its chitin component, could have immunostimulant properties and, therefore, can positively influence the broiler chicken health. Future behavioural and welfare studies will be required to confirm that live insect larvae can be used as natural environmental enrichment in intensive poultry farming.

\section{ACKNOWLEDGMENTS}

The research was supported by the European Knowledge and Innovation Community (KIC), within the EIT Food programme 'From waste to farm: insect larvae as tool for welfare improvement in poultry' (Project ID 19122). The authors are thankful to Entomics Biosystems (Cambridge, UK), which provided the live larvae throughout the experimental trial. The authors are also grateful to Mr. Dario Sola for bird care and technical support.

\section{ANIMAL WELFARE STATEMENT}

The authors confirm that the ethical policies of the journal, as noted on the journal's author guidelines page, have been adhered to and the appropriate ethical review committee approval has been received. The authors confirm that they have followed EU standards for the protection of animals used for scientific purposes and feed legislation.

\section{ORCID}

Sara Bellezza Oddon (D) https://orcid.org/0000-0001-8942-0682

Ilaria Biasato (D) https://orcid.org/0000-0002-8855-4248

Arianna Imarisio (D) https://orcid.org/0000-0002-6137-0377

Miha Pipan (D) https://orcid.org/0000-0001-8391-5924

Dominik Dekleva (D) https://orcid.org/0000-0003-1685-541X

Elena Colombino (D) https://orcid.org/0000-0002-6371-2000

Maria Teresa Capucchio (D) https://orcid.org/0000-0002-1068-0551

Marco Meneguz (D) https://orcid.org/0000-0001-8007-2044

Bergagna Stefania (D) https://orcid.org/0000-0001-5390-4108

Raffaella Barbero (D) https://orcid.org/0000-0003-4497-6382

Marta Gariglio (D) https://orcid.org/0000-0001-5224-8604

Sihem Dabbou (D) https://orcid.org/0000-0002-3525-1614

Edoardo Fiorilla (D) https://orcid.org/0000-0002-0173-1118

Laura Gasco (D) https://orcid.org/0000-0002-1829-7936

Achille Schiavone (D) https://orcid.org/0000-0002-8011-6999

\section{REFERENCES}

AOAC International. (2000). Official methods of analysis of AOAC International (17th ed.). AOAC International.

AOAC International. (2003). Official methods of analysis of AOAC International (17th ed., 2nd revision). AOAC International.

Aviagen. (2019). Ross 308 Broiler nutrition specification. Retrieved from http://eu.aviagen.com/tech-center/download/1339/Ross308308FF-BroilerPO2019-EN.pdf

Biasato, I., Gasco, L., De Marco, M., Renna, M., Rotolo, L., Dabbou, S. Capucchio, M. T., Biasibetti, E., Tarantola, M., Bianchi, C., Cavallarin, L., Gai, F., Pozzo, L., Dezzutto, D., Bergagna, S., \& Schiavone, A. (2017). Effects of yellow mealworm larvae (Tenebrio molitor) inclusion in diets for female broiler chickens: implications for animal 
health and gut histology. Animal Feed Science and Technology, 234, 253-263. https://doi.org/10.1016/j.anifeedsci.2017.09.014

Biasato, I., Gasco, L., De Marco, M., Renna, M., Rotolo, L., Dabbou, S., Capucchio, M. T., Biasibetti, E., Tarantola, M., Sterpone, L., Cavallarin, L., Gai, F., Pozzo, L., Bergagna, S., Dezzuto, D., Zoccarato, I., \& Schiavone, A. (2018). Yellow mealworm larvae (Tenebrio molitor) inclusion in diets for male broiler chickens: Effects on growth performance, gut morphology, and histological findings. Poulty Science, 97, 540-548. https://doi.org/10.3382/ps/pex308

Biasato, I., Ferrocino, I., Grego, E., Dabbou, S., Gai, F., Gasco, L., Cocolin, L., Capucchio, M. T., \& Schiavone, A. (2019). Gut microbiota and mucin composition in famale broiler chickens fed diets including yellow mealworm (Tenebrio molitor, L.). Animals, 9, 213. https://doi. org/10.3390/ani9050213

Bizeray, D., Estevez, I., Leterrier, C., \& Faure, J. M. (2002). Influence of increased environmental complexity on leg condition, performance, and level of fearfulness in broilers. Poultry Science, 81, 767-773. https://doi.org/10.1093/ps/81.6.767

Bruns, H. (1960). The economic importance of birds in forests. Bird study, 7, 193-208. https://doi.org/10.1080/00063656009475972

Bovera, F., Loponte, R., Marono, S., Piccolo, G., Parisi, G., Iaconisi, V., Gasco, L., \& Nizza, A. (2016). Use of Tenebrio molitor larvae meal as protein source in broiler diet: Effect on growth performance, nutrient digestibility, and carcass and meat traits. Journal of Animal Science, 94, 639-647. https://doi.org/10.2527/jas2015-9201

Campbell, T. W. (1995). Avian hematology and cytology (2nd ed.). lowa State University Press.

Dabbou, S., Gai, F., Biasato, I., Capucchio, M. T., Biasibetti, E., Dezzutto, D., Meneguz, M., Plachà, I., Gasco, L., \& Schiavone, A. (2018). Black soldier fly defatted meal as a dietary protein source for broiler chickens: Effects on growth performance, blood traits, gut morphology and histological features. Journal of Animal Science and Biotechnology, 9(49), 1-10.

Friedewald, W. T., Levy, R. I., \& Fredrickson, D. S. (1972). Estimation of the concentration of low-density lipoprotein cholesterol in plasma, without use of the preparative ultracentrifuge. Clinical Chemistry, 18, 499-502. https://doi.org/10.1093/clinchem/18.6.499

Gasco, L., Finke, M., \& van Huis, A. (2018). Can diets containing insects promote animal health? Journal of Insects as Food and Feed, 4, 1-4. https://doi.org/10.3920/JIFF2018.x001

Gasco, L., Biasato, I., Dabbou, S., Schiavone, A., \& Gai, F. (2019). Animals fed insect-based diets: State-of-the-art on digestibility, performance and product quality. Animals, 9, 170. https://doi. org/10.3390/ani9040170

Harper, G. C., \& Makatouni, A. (2002). Consumer perception of organic food production and farm animal welfare. British Food Journal, 104, 287-299. https://doi.org/10.1108/00070700210425723

Holmes, L. A., VanLaerhoven, S. L., \& Tomberlin, J. K. (2016). Lower temperature threshold of black soldier fly (Diptera: Stratiomyidae) development. Journal of Insects as Food and Feed, 2, 255-262. https:// doi.org/10.3920/JIFF2016.0008

Ipema, A. F., Gerrits, W. J. J., Bokkers, E. A. M., Kemp, B., \& Bolhuis, J. E. (2020). Provisioning of live black soldier fly larvae (Hermetia illucens) benefits broiler activity and leg health in a frequency- and dose-dependent manner. Applied Animal Behaviour Science, 230, 105082. https://doi.org/10.1016/j.applanim.2020.105082

IPIFF. (2020). The insect sector milestones towards sustainable food supply chains. Retrieved from https://ipiff.org/the-insect-sector-miles tones-towards-sustainable-food-supply-chains/

Koene, P. (1999). When feeding is just eating. How do farm and zoo animals use their spare time? In D. van der Heide, E. A. Huisman, E.
Kanis, J. W. M. Osse, \& M. W. A. Verstegen (Eds.), Proceedings 5th Zodiac Symposium Wageningen, The Netherlands, 13-19.

Kogut, M. H., \& Arsenault, R. J. (2016). The new paradigm in food animal production. Frontiers in Veterinary Science, 3, 10-13. https://doi. org/10.3389/fvets.2016.00071

Koštál, V. (2006). Eco-physiological phases of insect diapause. Journal of Insect Physiology, 52, 113-127. https://doi.org/10.1016/j.jinsp hys.2005.09.008

Lumej, J. T. (2008). Avian clinical biochemistry. In J. J. Kaneko, J. W. Harwey, \& M. L. Bruss (Eds.), Clinical biochemistry of domestic animals. Elsevier Academic Press.

Magdelaine, P., Spiess, M. P., \& Valceschini, E. (2019). Poultry meat consumption trends in Europe. Wolrd's Poultry Science Journal, 64, 5664. https://doi.org/10.1017/S0043933907001717

Newberry, R. C. (1995). Environmental enrichment: Increasing the biological relevance of captive environments. Applied Animal Behaviour Science, 44, 229-243. https://doi.org/10.1016/0168-1591(95)00616-Z

Nunes, R. V., Broch, J., Wachholz, L., de Suoza, C., Damasceno, J. L., Oxford, J. H., Bloxham, D. J., Billard, L., \& Pesti, G. M. (2018). Choosing sample sizes for various blood parameters of broiler chickens with normal and non-normal observations. Poultry Science, 97, 3746-3754. https://doi.org/10.3382/ps/pey217

Qin, W., \& Walker, V. K. (2005). Tenebrio molitor antifreeze protein gene identification and regulation. Gene, 367, 142-149. https://doi. org/10.1016/j.gene.2005.10.003

Riber, A. B., Van De Weerd, H. A., De Jong, I. C., \& Steenfeldt, S. (2018). Review of environmental enrichment for broiler chickens. Poultry Science, 97, 378-396. https://doi.org/10.3382/ps/pex344

Robins, A., \& Phillips, C. J. C. (2011). International approaches to the welfare of meat chickens. World's Poultry Science Journal, 67, 251-269. https://doi.org/10.1017/S0043933911000341

Salamano, G., Mellia, E., Tarantola, M., Gennero, M. S., Doglione, L., \& Schiavone, A. (2010). Acute phase proteins and heterophil:lymphocyte ratio in laying hens in different housing systems. Veterinary Record, 167, 749-751. https://doi.org/10.1136/vr.c5349

Scheuermann, G. N., Bilgili, S. F., Hess, J. B., \& Mulvaney, D. R. (2003). Breast muscle development in commercial broiler chickens. Poultry Science, 82, 1648-1658. https://doi.org/10.1093/ps/82.10.1648

Star, L., Arsiwalla, T., Molist, F., Leushuis, R., Dalim, M., \& Paul, A. (2020). Gradual provision of live black soldier fly (Hermetia illucens) larvae to older laying hens: Effect on production performance, egg quality, feather condition and behavior. Animals, 10(2), 216. https://doi. org/10.3390/ani10020216

Veldkamp, T., \& van Niekerk, T. G. C. M. (2019). Live black soldier fly larvae (Hermetia illucens) for turkey poults. Journal of Insects as Food and Feed, 5, 301-311. https://doi.org/10.3920/JIFF2018.0031

Zuidhof, M. J., Molnar, C. L., Morley, F. M., Wray, T. L., Robinson, F. E., Khan, B. A., Al-Ani, L., \& Goonewardene, L. A. (2003). Nutritive value of house fly (Musca domestica) larvae as a feed supplement for turkey poults. Animal Feed Science and Technology, 105, 225230. https://doi.org/10.1016/S0377-8401(03)00004-X.

How to cite this article: Bellezza Oddon S, Biasato I, Imarisio $A$, et al. Black soldier fly and yellow mealworm live larvae for broiler chickens: Effects on bird performance and health status. J Anim Physiol Anim Nutr. 2021;00:1-9. https://doi. org/10.1111/jpn.13567 